\title{
Five Codes of Barthes: A Post-structuralist Analysis of the novel The Colour of Our Sky
}

\author{
by Amita Trasi \\ * Aisha Jadoon, Assistant Professor \\ ** Ali Naqi, PhD Scholar \\ *** Dr. Uzma Imtiaz, Assistant Professor
}

\begin{abstract}
Barthes's five-code theory puts forward the idea of the reader as a producer of the text rather than its consumer. This typology of the codes, which constitutes plurality of the text, offers different meanings beyond the boundaries and limitations of the particular time and place. Thus, Barthes' theoretical contribution is credited for rescuing the reading of fiction under the pressures of a local cultural to a more global orientation. Acknowledging the 'rewriting' of the text by readers, this paper adopts Barthes' theory that includes proairetic, cultural, hermeneutic, semantic and symbolic codes, as an analytic method to examine the text The Colour of Our Sky written by Amita Trasi (2017) for the identification of what lies beyond the text, a network of collective socio-cultural norms that invokes complex modulations of meanings informed by the relations of discourse, power and subjectivity in different historical periods and in certain social and geographical spaces.
\end{abstract}

Keywords: Five codes, Poststructuralism, Narratives

Introduction

Post-structuralism in literature has resulted in the replacement of textual approaches to fiction with that of philosophical and critical approaches. It prefers reader centered approaches over approaches that consider the author as the ultimate source of meaning making. Post-structuralism, while revoking the canons of structuralism, i.e., 'the unity of stable sign', puts emphasis upon the interaction of reader and text. By stretching the notions of structure, poststructuralists provide a critique of the determinacy and stability of language that attends our sense of reality. Post-structuralism, to a great deal, follows Saussure's philosophy of language. The followers of the structuralist and poststructuralist traditions do not restrict language to the written and spoken domains, but consider language as central to their very conception of the world view. However, post-structuralists believe that meaning is intrinsically unstable because of the play of signs within language. To put it simply, language encodes both the signifier and signified to offer meaning to the word or phrase used. For example, the word 'FISH' a signifier, can have many signified depending upon the number of readers. It may be goldfish, shark, trout or any other fish. The conception of meaning variability was proposed by Derrida (1976) in his theory of difference.

The point of departure for the post-structuralists from a structuralist idea of language is the negation of the fixity of the truth hidden in language. Truth is not an objective fact but a subjective experience that has no shared determinacy (Harcourt, 2007). In addition to this, Roy (2017) also suspends the possibility of language to offer an access to the objective reality that exists therein. Though comprehended by the language, it is always relative to the subjective consciousness. (Roy, 2017c) Therefore, the essential notions of language as mirror to logocentric view of truth are rejected by the post-structuralists critics. Language, thus, is conceptualized as an assemblage of differentiated signs. (Pada, 2007)

Foucault (1980), like Derrida (1974), also argues against the structuralist conception of language autonomy and universality i.e. with its own rules and functions. He explores specific and determinate historical conditions in which the discourse or statement is regulated under a specific setting, the regime of truth. For Foucault, it is power, not the fixed signs, that temporarily stabilizes the meanings into discourse. Power-centered discourse determines what is true and according to norm

\footnotetext{
* Department of Humanities, COMSATS University, Islamabad, Pakistan

Email: aisha.jadoon@comsats.edu.pk

** Foundation University, Islamabad, Pakistan

*** Fatima Jinnah Women University, Rawalpindi
} 
and what is wrong and unacceptable. He further explains that discourse not only regulates what is said in a specific cultural and social setting, but also determines who is saying.

In the similar fashion, Butler (1990) also disapproves structuralist ideas as "the claims of totality and universality and the presumption of binary structural oppositions that implicitly operate to quell the insistent ambiguity and openness of linguistic and cultural signification" (p. 40). She advocates the post-structuralist notion of unpredictability of the signs within linguistic domains. Truth is never dependent on the language codes. In contrast, to structuralists strictness of linguistic norms, she suggests the need to attend to the differences that exist which occur "as a result, the discrepancy between signifier and signified becomes the operative and limitless difference of language, rendering all referentiality into a potentially limitless displacement" (Butler 1990, p. 40).

Barthes (1974) is a key theorist of post-structuralist idea of truth. He postulates that the meaning of a text is not set. He argues that the role of readers should be active rather than passive. The readers should actively interpret the text instead of looking at fixed, single or final meanings. He challenges the restrictive reading experience under structuralism that counts the cultural conception as meaningless. For him, the meaning making is not the solitary domain of the author individually who only knows the truth. It is the process in which readers equally play an active role by being aware of the cultural content of the text that establishes the multiplicity of meaning. Bowman (2015) mentions:

What "goes into" the writing or production of any text is never anything other than already culturally circulating material-words, phrases, techniques, styles, and conventions that are not unique to an individual, but that only exist and "work" because they are part of the fabric of communication, community, and discourse. Barthes calls this "textuality." Communication of all kind works on the basis of intertextuality. Works are stitched together from existing cultural material, i.e., words, signs. (p.2)

While rejecting the authority of the author, Barthes (1974), like Derrida, also targets the power of social and political institution. Barthes's "From Work to Text" and "The Death of Author", the two essays, clearly target the power held the institution that makes people believe in the given meaning or explanation of a text. According to him, the subordination of a subject (reader) to the authorities (power institutes; universities, professors, teachers, study centers) in fact paves way to maintain status quo rather than giving freedom to interpret the text personally. (Weber, 1987) Owing to this fact, Derridean's theory on deconstruction widely hailed and was regarded a tremendous approach to interpret a work freely. However, at the same time Derrida's work along with other poststructuralists such as Julia Kristeva and Judith Butler was targeted with hostility and confusion by many other readers.

By considering the views of post-structuralists, it can be stated that post-structuralism is associated with words and wordiness. However, this does not mean that post-structuralism deals with unitary system like structuralism. It has many variants and dimensions. Belsey (2002) in his article on post-structuralism argues that in text "language is a medium by which a single idea can be interpreted into multiple meanings" (p. 5). Due to this freedom, the idea of multiplicity of meanings widen the scope of analysis of literary pieces such as stories, novels and poems. By considering this language flexibility, multiple and differing readings of a single literary piece becomes understandable. Barthes (1974), for his theory of five codes, is credited as a major theorist to dispel the unnecessary influence of author on the meaning making process of a literary piece. The traditional practice of interpreting a narrative, i.e., the practice of close reading of the text or the practice of reaching the ultimate view of the author is abandoned by the poststructuralist critics. Further, he states that in the process of meaning making and interpretation, the participant produces a layer of meanings as the text is a collection of signifiers (Barthes, 1974). In this regard, his five codes as analytical tool to interpret the meaning which helps the reader to understand the narratives. His essay S/Z, defines and explains these post-structuralist codes as "mirage of structures, the sign of virtual digression, one of the voices that can take over the text, one of the voices out of which the text is woven" (Barthes, 1974, p. 20). This theory of determining meaning offers a significant assistance in uncovering the voices and hidden meanings encoded in the language of a literary narrative.

This paper selects The Colour of Our Sky written by an Indian novelist, Amita Trasi (2017), to draw the relationship between the literary and cultural to determine the meanings of the text. The novel is set in the late eighties of Indian society. The story of the novel revolves around coming of age 
of a young female character named as Mukta. The narrative opens with the village protagonist, a lower-caste "Yellama" (a patron goddess of the South Indian States, namely Andhra Pradesh, Karnataka and Tamil Nadu) when she was only ten years old. The fact of her being 'ten years' old is important to be considered since it was considered a time in the life of a girl from her caste when she was destined to become a temple prostitute. This was an old generational ritual in which both her mother and grandmother had practiced before. Mukta, for being scared of this outlawed ritual which was the fate of each and every girl of the society, was sent to serve as a housemaid for a rich family in Mumbai to escape her fate as a prostitute. This family had an eight -year- old daughter, Tara, who was quite sympathetic on hearing about her miserable past. She introduced Mukta to a world that was altogether different from the world that was known to her. During her stay with the family, both the girls developed the strong bonding of sisterhood. Then comes a sudden twist in the story when one night in 1993, Mukta got abducted without any hint of trace. Sometime later, Tara's family immigrated to America after the kidnapping of Mukta. However, this transition from her native city to the cosmopolitan city of Los Angles couldn't help Tara to overcome the grief of losing her friend-cum sister, Mukta. The memories of her friend stayed with her even after twenty years of her stay away from her native birthplace. The lapse of twenty years created innumerable challenges for Tara who wanted to trace the whereabouts of Mukta. In the course of her search, by chance her confrontation with a notorious and brutal underground organization exposed her to the sordid existence of human trafficking in Indian society.

It is from these vectors of a personal loss of a sisterhood to the social existence of human trafficking of the literary-cultural domain for an understanding of the reality that this paper draws its rationale to apply Barthes's theory of five codes to understand the truth value of the text set in nineteenth century India to be analyzed.

\section{Roland Barthes' Theory of Five Codes}

Considering the breadth of Barthes' theory of five codes, this paper selects it to examine the thematic orientations of the selected text. Barthes categorizes the five codes as proairetic code, the hermeneutic code, the semantic code, the symbolic code, and the cultural code. By introducing these codes, however, he does not suggest the presence of these codes simultaneously in text. This possibility is precluded by the diverse nature and form of different narratives. Different narratives may exploit codes to disseminate the voice of the narrator. The explanation of these codes is given below:

Proairetic code is the first code of Barthes theory, which is identified by Eagleton (2011) as "Narrative Code". (p. 120) This code helps to determine those conflicting and contradictory components that give rise to the major conflicts of the narrative plots. These components are responsible for generating the element of suspense in a narrative. They not only propel the plot of the narrative forward but also arouses the reader's curiosity to know how the tension gets resolved in the course of the narration. This curiosity prompts the questioning nature of the readers when they try to guess the expected sequence and reactions of the narrative happenings in advance.

Hermeneutic code is the second important code of Barthes' theory of five codes. This code majorly focusses on interpreting the text. Originally it was used to interpret and bring out the meanings of biblical texts. Selden, Widdowson \& Brooker (2005) also regard this as "code of enigma" because of uncovering those components that confuses the reader by making them look strange and enigmatic. This happens at a point when the reader attempts to know the secrets by questioning their prior knowledge. For this suspensive and conflicting situation, Felluga explains some distinctive terms which Barthes uses. These are "snare", "equivocations", "partial answers" and "jammings". While the word "snare" refers to "deliberate evasion of truth", term "equivocation" indicates "mixture of truth and snare". The word "jammings" refers to "acknowledgement of insolubility" (Felluga, 2014). Such words give allegorical interpretation of the subordinate elements that label the complex conditions and happenings of a literary text.

Semantic code is the third code, which is also titled as the connotative code by Barry (2002, p. 151). The semantic code necessitates the understanding of the connotations of the elements of the text to get their implied meanings. Such an understanding can help the readers to know those specific "characters, places and objects" which according to Zaib and Mashori (2014) are essential for the understanding of the text. 
Barthes (1974) explains the fourth code of his "theory of code" as symbolic code which otherwise is labelled as "antithetical code" (p.19). This code performs its function like semantic code. Due to its close resemblance with "semantic code", sometimes it becomes too difficult for a reader to distinguish "symbolic code" from "semic code". This ambiguity arises, according to Felluage, due to failure on Barthes part to distinguish the two. However, this code was originally intended to recognize those antithetical components of the text that help the readers to make sense of the text. (Felluga, 2014) The readers, by considering this code, can precisely focus on the binary polarities.

The fifth and last code of Barthes' theory of five codes is regarded as the cultural or referential code. The cultural code comprises of the collective universal knowledge shared by the readers. This code also enables the readers to focus on the several properties of the characters in a story such as "physical", "physiological", "psychological", "literary" and "historical". The close consideration of these properties paves way to determine the multiple meanings of the text.

\section{Analysis of The Colour of Our Sky (2017) by Amita Trasi}

\section{The Proairetic code}

The Proairetic code that is also known as native code is opted at the first place to analyze the text. For this purpose, three lines from different chapters of the novel are selected. In the first chapter, Tara has just returned from America after the death of her father. She reaches her home that was closed from a decade. Everything is covered in dust, however, the bit and pieces of her house reminds her the past and the close company of Mukta. She decides to go to police station to file a complaint about the abduction of Mukta. The Proairetic code which denotes the suspense in narratives operates on two levels. On one level, it drops hint that something is about to happen, on the other level it prompts the resolution of the tension by the readers. The following lines in which Tara is seen to visit Police station so as to know about Mukta, give hints to the reader that not only Tara will be provided with information about her friend but the mystery of her kidnapping will also be solved. Tara is waiting for the bus on rout to police station when a taxi driver comes and asks from her:

Madam, I taking you anywhere you wanting to go," a taxi driver called out. "No here, here..." another taxi driver waved. I nodded to one of them and he hurriedly got behind the wheel. It began drizzling as I stepped inside. The rain fell softly around us. Take me to the police station in Dadar, I told him. Madam, you coming from foreign, no? I understanding from the way you speaking. I taking you to the best hotels in Mumbai. You will...' Take me to the police station, I repeated sternly. (Trasi, 2017, p. 03)

The action and reaction system is the defining feature of the narrative code arises. Tara expects that during these years police would have recovered Mukta, if not, at least they can give information about her. On the other side, readers also await for the reaction from this initiation. However, the proceeding of this action goes despondently reflecting the true police culture of subcontinent. The knowing of Mukta's whereabouts is protracted when the author employs a scene which makes her to run away from home. This triggers an action and reaction chain in the story. Mukta asks her grandmother about the arrival of different men at their home. She also asks a question about her father from these men. The time of Indian society which the story alludes to was when the females of lower caste were not considered to marry in the states of Karnatka, Andhra Pradesh, and Kerala etc... They were perceived as the beings only to serve the men of upper class on the name of Yellama, a goddess, who was believed to bless them their destiny if they became prostitute. The question (action) is asked by Mukta to know the answer (reaction) who was her father from among those men her mother slept with. She asks, "Why do these men come to visit Amma? Is one of them my father? I asked softly, so softly it sounded like a whisper. "Ah," Sakhubai (grandmother) said," it is time you should know" (Trasi, 2017, p. 19). Upon asking this question, Mukta's grandmother calls her by her side. She then tells her that they are from lower class and they have taken vow from generations to dedicate all daughters to goddess Yellamma. For this purpose, when a girl reaches at a certain age, she is properly dedicated to the goddess in a ceremony. Sakhubai, Mukta's grandmother was dedicated when she was hardly eight years old in a ceremony. So did happen with Mukta's mother and now the same will happen with Mukta.Owing to this reason Mukta runs away from home showing her rebellion to the rituals.

After this flashback, Tara is now in the police station, asked by Mr. Chitale, the person on duty, about Mukta. Tara says, "I am looking for (action) a girl Mukta, who was rescued by my father 
(Ashok Deshmukh)". Upon this question, Chitale, the police man replies (reaction) that five years ago the cupboard, in which files of different cases were kept, was eaten up by the termites, so all the damaged files have been discarded. However, luckily before destroying those files they entered all the necessary information into the computer. The police man then checks the record which shows five Muktas. All those girls were orphans who were recently been sent to the orphanage center for care.

\section{The Hermeneutic Code}

Hermeneutic code, also known as the "code of enigma" (Selden, Widdowson \& Brooker, 2005) designates all the confusing, indistinct and mysterious elements of a text that makes readers curious to unveil the mystery.

The mystery of Mukta's paternity remained for a long time as it couldn't be established whether she was the daughter of a temple prostitute or the daughter of her real father to whom her mother got married. Often she asked questions to her grandmother (Sakhubai) and mother (Amma) who was her father. Especially when she looked at families shopping in the bazar, she felt that something was missing in her life:

I always feel afraid when I say something that reminds her (Amma) of my father, and at times when I do ask, her eyes melt into that forlorn, heartbroken look. So I let her continue with her stories, never stop her to ask if my father wants to meet me. I'll wait, I tell myself (Trasi, 2017, p. 16).

One puzzle is that Mukta's mother (Amma) did not answer the question regarding who her real father was, another puzzle was when she (Amma) one day called Mukta to sit beside her as she wanted to tell her something.

One morning I heard Amma's sweet voice calling out to me. Mukta, Mukta, come here my child. I will call your father. I don't know which part of Bombay he lives in, but I know someone in this village your father's mother --- your grandmother --- and she has promised to give me a telephone number where I can call him (Trasi, 2017, p. 29).

This led Mukta into another confusion who her father can be. If her father's mother is in the same village, why did she never see her father? All this happened when a madam from the same village visited Sakhubai's (grandmother) home where Mukta was living with her mother (Amma) and grandmother (Sakhubai). Her visit was to see whether Mukta was ready for the goddess Yellama ceremony or not. Her mother could forsee the future of Mukta. To give hint that the mother of her father lived in the same village meant that her father was a zamindaar of the village to whom Mukta's mother had been serving as devadasi.

Kidnapping is also a mystery, about which Tara is worried. The long time shows how great the enigma of abduction is. No whereabouts have been found about this incident from eleven years.

'It is about a kidnapping that happened eleven years ago. A girl was kidnapped. My father

filed a report then." Eleven years? The constable raised his eyebrows. And you want to search for her now? (Trasi, 2017, p. 05).

The long time, on the one hand shows the slow investigative police system and on the other hand reflects the influence of powerful social fabric. The misplacement of record which shows the factor of carelessness also increase the curiosity of abduction.

\section{The Semantic and the Symbolic Code}

The semantic code identifies the elements of a text (characters, concepts or objects) which imply double meaning and grasp their connotative and hidden meanings. One such concept is that of 'devadasi' used recurrently in the text. In orthodox Hindu culture, the word Devadasi refers to fallen women who devote their lives as being traditional dancers. The life style of remote and distant parts of India reveals a paradoxical dynamics: a contest between upper-class and lower-class, patriarchy and femininity, orthodox and unorthodox and so on. (O'Flaherty, 1981) Among Hindus, the same paradoxical attitude exists about Devadasi. In contemporary situation, at one time Devadasis feel fear of sexuality unless domesticated within marriage and the other time, at another time, these Devadasis are, in South Indian state of Karnataka, regarded as the co-wives or consorts of the Hindu god Siva. (Nair, 1994) They are also known as auspicious being or forever auspicious married woman since they do not become widows as their husbands are divine [gods]. In temple they are found with begging baskets with ritual divine containment such as vermilion powder with which they welcome the visitors. Their entire life reflects or mirrors the ritual cycle of Yellamma goddess as "chaste-wife", 
"degraded-wife" and a "pious-wife" (Evans, 1998). Following are different roles of Devadasis in the novel.

\section{Devadasi}

According to the southern Indian culture, a girl by becoming devadasi spends her entire life to serve the temple and worship the diety of the temple. This transition from an ordinary village girl to devadasis takes place in ceremony similar to the marriage ceremony. This ceremony is called a Pottukattu ceremony. The dance performances and music played are essential features of temple worship. In the novel, devadasi performs all rituals at the temple of goddess Yellama and also serve the people of upper class. It is also known as temple prostitute. The caste from which Mukta belongs is a lower class in Indian tradition. The women of this caste always serve either for rich on the name of religion. Like Mukta, her mother, her grandmother and the mother of grandmother all have been serving since generations to the influential people of society without feeling belittle since this practice turned into a religious exercise. (Trasi, 2017)

\section{Yellama}

Hindu temple, Yellamma, which is also called Renuka Temple, located in the Indian state of Karnataka, a holy place of Hindu worship. The deity of fertility goddess Yellamma or Ellama or Renuka, contained in this temple is revered by Hindu pilgrims. This temple is known for its celebration of the Devadasi ritual through which the young girls of the lower caste are made the temple prostitutes. In contemporary times, this practice is claimed to be abolished by the local government. In the novel, it serves the purpose to dedicate young girl in a ceremony to the people of upper class. Whenever a girl reaches a ripe age, she is brought to the temple for the ceremony. Mukta is also brought here as a sacrificial commodity. Paradoxically, the very arrangement of this ceremony resembles to that of marriage ceremony. Girls in red Saarhi appear in front of the goddess and devote their whole life in temple. (Trasi, 2017)

\section{Nitya Sumangali}

In the novel, Mukta, her mother and grandmothers are Nitya Sumangali. According to traditions they are only to sleep with men in the name of goddess Yellama. They believe themselves as the servants of goddess and the wife of the entire village. They are also free from widowhood as they do not marry a man. They have the privilege of marrying the goddess.

\section{The Cultural Code}

The fifth and last code of Barthes' theory of five codes is regarded as the cultural or referential code. The cultural code contains those components that comprise of the shared world knowledge. In the novel, while discussing the case of Mukta with the constable, Tara now plans to return. Tara's habit of smoking in the police station in the presence of two police constables in a typical smoker's style casts her abhorrent glances of those around her. In Indian culture, smoking is considered as an exclusively male practice, therefore a female smoker is viewed as a transgressor of feminine ideals; whereas in Europe and America it is accepted as an ordinary practice of both males and females. It also marks a sign of freedom, modernism and, more above this, an act of vulgarity that gives way to some other blames upon a girl such as a gangster, a member of a drug mafia, a pimp etc... Similarly, the lone travelling of Tara also shows that she is independent and rebellious spirit who does not regard the ideals of femininity. She goes to the restaurant at night, to order a sandwich and a cup of tea which are the hints of her western lifestyle.

My first cigarette had been in America with Brian when I was eighteen. Brian, my fiancé had once been the love of my life, and I had conveniently left him behind in Los Angeles. If things had been changed, Brian and I would have be lolling lazily on a beach right about now, watching the waves surge and recede (Trasi, 2017, p. 10).

These lines evidently tell that Tara is accustomed to American culture which is not considered good and sophisticated in India, especially in remote and distant areas where people are still under the influence of supernatural and conventional beliefs.

On the other hand, Saarhi and more particularly red Saarhi evokes the image of traditional marriage ceremony. The grandmother describes her past when she wore red Saarhi to be a devadasi. Wearing Saarhi, for these people pertains to be a goddess property. However, the concept of this dress in other culture is different from the women of Yellama goddess: "Oh! I glowed like a bride in a red 
Saarhi and for hours the priest chanted mantras and flicked rice over my head. After that ... she let out a deep sigh. Life was different after that..." (Trasi, 2017, p. 49)

There are also some other cultural referents in the novel such as silk dhoti, crisp kurta etc. which invoke different connotation in other cultures. However, in southern parts of India, only brides wear silk sarees on their own wedding days. For being expensive, silk dresses are used as a royalty symbol of the elite class; on the other hand, wearing of the cotton dresses was taken as a sign of poverty. In subcontinent, more specifically in Indian culture, the gods in Hinduism, are dressed with silk clothes. Similarly, the land owners also wear silk dhoti as a symbol of authoritative and influential man in society. Unlike Hindu culture, Islam forbids Muslim men from wearing the silk. Men do not wear silk dress but for women it is allowed. In this regard, a number of religious jurists believe that wearing silk clothing hide manliness. It makes a man more like feminine. It is also regarded as an act of extravagancy. However, there are disputes regarding the amount of silk that a fabric can consist of (i.e., whether a small decorative silk piece on a cotton caftan is permissible or not) to make it lawful for men to wear, but the most prevalent opinion of many Muslim scholars is that the wearing of silk for men is forbidden. Despite injunctions against silk for men, silk has retained its popularity in the Islamic world because of its permissibility for women.

\section{Conclusion}

This study concludes that the language of the text is not fixed in terms of its construction and representation of an ultimate reality. Such an understanding of language is one constructed through the logic of five-code theory, whereby the words escape the boundaries of time, space and culture. In this sense, the words of the text do not hold fixed truths and positions from which one can stand and take account of the meaning as a whole. Thus, Barthes' codes help readers to think about multiplicity and to think about the complexity of semiosis. The use of Barthes' theory of five codes as an analytical tool to attend to various voices of the selected text helps the reader to understand the complex dimension of the feminist themes. The word Devadasi, Nitya Sumangali in one particular culture are associated with a sacred and revered purpose whereas in other cultures these words give completely opposite meaning. Similarly, Tara's smoking and dating with Brian in America mark her freedom of actions as the same style of life in Indian culture is considered vulgar and immoral. At the same time, the role of police and taxi driver is very conventional in these cultures, which is very different from Europe and America. Silk dress, in Hindu culture suggests the sign of royalty, gentry and being a superior man of the society whereas in Muslim culture it is considered as an act of extravagancy. It also resembles a feminine choice and is prohibited for men. Besides, silk dress for women also designates a special dress for wedding events, parties or other high level social events. It is, thus, concluded that Barthes five-code theory present extremely productive model for the readers to generate a multidimensional view of reality in the reading of a single text.

\section{References}

B. Negi. (2005). Muslim Men Not to Wear Silk \& Gold: Quran,"TheMuslimWomen.org. Retrieved February 14, 2011.

Barry, P. (2002). Beginning Theory: An introduction to Literary and Cultural Theory. 2nd ed. Manchester: Manchester U P.

Barthes, R. (1974). S/Z. (R., Miller, Trans). London: Blackwell Publishing Ltd.

Barthes' Five Codes. Retrieved May 24, 2014 from http://changingminds.org/disciplines/storytelling/ articles/barthes_five_codes.htm

Belsey, C. (2002). Post-structuralism: A very Short Introduction. New York: Oxford U P.

Bowman, P. (2015). Poststructuralism. The International Encyclopedia of Political Communication, $1-5$.

Butler, Judith. (1990). Gender Trouble: Feminism and the Subversion of Identity. New York: Routledge.

Derrida, J. (1976). Of Grammatology. Translated by G. C. Spivak. Baltimore, MD: Johns Hopkins University Press.

Derrida, J. (1982). Margins of Philosophy. Brighton, UK: Harvester

Eagleton, T. (2011). Literary theory: An Introduction.New York: John Wiley \& Sons.

Evans, K. (1998). Contemporary 'Devadasis' Empowered Auspicious Women or Exploited Prostitutes. Bulletin of the John Rylands Library, 80(3), 23-38. 
Felluga, D. (n.d.). Modules on Barthes II: On the five codes. Retrieved May 24, 2014 from http://www.cla.purdue.edu/english/theory/narratology/modules/barthescodes.

Foucault, M. (1972).The Archaeology of Knowledge. New York: Pantheon.

Foucault, M. (1980). Power/Knowledge. New York: Pantheon

Harcourt, B. (2007) An Answer to the Question: 'What Is Poststructuralism?'[pdf] Chicago: University of Chicago. Available at: http://moodle.bcu.ac.uk/pluginfile.php/1469558/mod resource/content/1/An\%20Answer\%20to\%20the\%20Question\%20\%20What\%20Is\%20Postst ructuralism.pdf [Accessed 20/01/2018].

Nair, J. (1994). The Devadasi, Dharma and the State. Economic and Political Weekly, 3157-3167.

O'Flaherty, W. D. (1981). Siva: The erotic Ascetic. Oxford University Press.

Pada, R. T. S. (2007) The Paradox of Ipseity and Difference: Derrida's Deconstruction and Logocentrism. KRITIKE, 1(1). Available at: http://www.kritike.org/journal/issue_1/pada_june 2007.pdf [Accessed 20/01/2018].

Roy, J. (c2017) Basic Differences Between Structuralism and Post-Structuralism. Available at: https://sites.google.com/site/jeffsliteraturecafe/basic-differences-between-structuralism-andpost-structuralism [Accessed 21/01/2018].

S. al-Oadah, "Ruling on men's neckties and on men wearing silk,"IslamToday.net (no date). Retrieved February 14, 2011.

Selden, R., Widdowson, R., \& Brooker, P. (Eds). (2005). A Reader's Guide to Contemporary Literary Theory. 5th ed. London: Pearson Longman.

Trasi, A. (2017). The Colour of Our Sky, Thomsan Press India, India.

Weber, S. (1987).Institution and Interpretation. Minneapolis. MN: University of Minnesota Press.

Zaib, S., \& Mashori, G. M. (2014). Five Codes of Barthes in Shahraz's Story A Pair of Jeans: A PostStructural Analysis. ELF Annual Research Journal, 16, 171-184. 